\title{
NESTOR DE FIGUEIREDO E O URBANISMO DAS CIDADES DO "NORTE" ${ }^{1}$ \\ Francisco Sales Trajano Filho
}

\section{Resumo}

O artigo atém-se a investigar as proposições no campo do urbanismo que o arquiteto Nestor Egydio de Figueiredo passa a elaborar a partir do trabalho de remodelação urbana para o Recife apresentado durante o IV Congresso Pan-Americano de Arquitetos, continuadas nas muitas iniciativas empreendidas por ele no decurso de seu périplo por vários estados nordestinos na década de 1930. A análise é focada, sobretudo, em torno do plano concebido para a cidade de João Pessoa, conduzido simultaneamente àquele para o Recife e o único dos projetos a se implantar de fato, para a surpresa do próprio urbanista. A intenção é mostrar como Figueiredo é ao mesmo tempo tributário e partícipe da cultura urbanística em formação no Brasil, atravessada por não poucas ideias e práticas do urbanismo internacional que por meios diversos aportava no país, adensando o debate acerca das cidades e seu futuro, tão candente nesse momento.

\section{Palavras-chave:}

Nestor de Figueiredo, urbanismo no Brasil, Nordeste

\section{Abstract:}

Thispaper investigate the propositions in the field of urbanism by the architect Nestor Egydiode Figueiredo in several northeastern states from Brazil in the 1930s. The analysis is focused mainly around the plan designed for the city of João Pessoa, conducted simultaneously that for Recife and the only project to deploy in fact, to the surprise of their own planner. The intention is to show how Figueiredo is both tributary and participant of the urbanisticculture in formation in Brazil, crossed by not a few ideas and practices of urbanism international that by different means arrived in the country, thicken the debate about the Brazilian city and its future, as burning at this time.

\section{Key-words:}

Nestor de Figueiredo, Urbanism in Brazil, Northeast

\footnotetext{
${ }^{1} \mathrm{O}$ autor agradece à FAPESP (Fundação de Amparo à Pesquisa do Estado de São Paulo), pelo apoio financeiro (proc. n.2013/00645-1) que viabilizou sua participação no 10 SeminárioTrajetórias (biografias?) profissionais: Urbanistas e Urbanismo no Brasil, realizado na Universidade de Brasília, entre 10 e 12 de abril de 2013, onde este trabalho foi originalmente apresentado.
} 
"Os planos das cidades deverão ser traçados dentro de princípios técnicos que atendam de preferência às necessidades coletivas, tomando em consideração a vida urbana desenvolvida em harmonia com os progressos morais e materiais de nosso século"

Nestor Egydio de Figueiredo

"Um dos arquitetos brilhantes da atual geração brasileira" (COSTA, 1927: 285), como é apresentado por Angyone Costana introdução à entrevista concedida para o livro A inquietação das abelhas (1927) -espécie deradiografia do campo artístico e cultural da capital federal no final da Primeira República capturada através de depoimentos dospróprios personagens -o arquiteto e urbanista Nestor Egydio de Figueiredo (1893-1973) é um daqueles casos, tão encontradiços na historiografia, cuja trajetória pessoal e profissional conhece-se apenas por fragmentos de relatos desconexos, referências dispersas e eventuaisno interiordas narrativas de formação da arquitetura e do urbanismo no Brasil do século $\mathrm{XX}$.

Egresso da Escola Nacional de Belas Artes (ENBA), onde se forma em 1917, logo afamado como arquiteto engajado na campanha neocolonial conduzida no Rio de Janeiro sob o mecenato do médico José Marianno Carneiro da Cunha Filho (18811946), pernambucano radicado na capital federal tal como ele próprio, Nestor de Figueiredo é listado por Philip Goodwin entre os"que seguiram in loco este estudo da arquitetura brasileira" (GOODWIN, 1943:8), em alusão ao trabalho de levantamento para a escrita de Brazil Builds (1943).Lúcio Costa reconhece seu "espírito tutelar" na defesa dos interesses da classe profissional dos arquitetos numtrecho deDepoimento de um arquiteto carioca (1951) (XAVIER, 2007:186-187), enquantoPaulo Santosassinala sua presença emdistintos momentos da história da arquitetura no Rio de Janeiro contada em Quatro séculos de arquitetura(SANTOS, 1977).

Já Yves Bruand, embora circunscrevaa presença de Figueiredo em Arquitetura contemporânea no Brasilaos desdobramentos iniciais do neocolonial, destaca as qualidades na operação de transplante e ajuste de motivos coloniais ao Pavilhão das Pequenas Indústrias, na Exposição Internacional do Centenário da Independência (1922), projetado em coautoria com C. S. San Juan (BRUAND, 1999:55).Além de participar de vários concursos relativos às obras da exposição do centenário, são da lavra de Figueiredo os projetos do Pavilhão das Indústrias Particulares, a partir de adaptações no já existente Mercado Municipal, e o Pavilhão da Música, considerado, 
no Relatório dos trabalhos do evento, o "remate natural da evolução arquitetônica que o arquiteto Nestor de Figueiredo estabeleceu em sua obra de exposição iniciada com o Pavilhão das Pequenas Indústrias" (LEVY, 2010: 198-204).
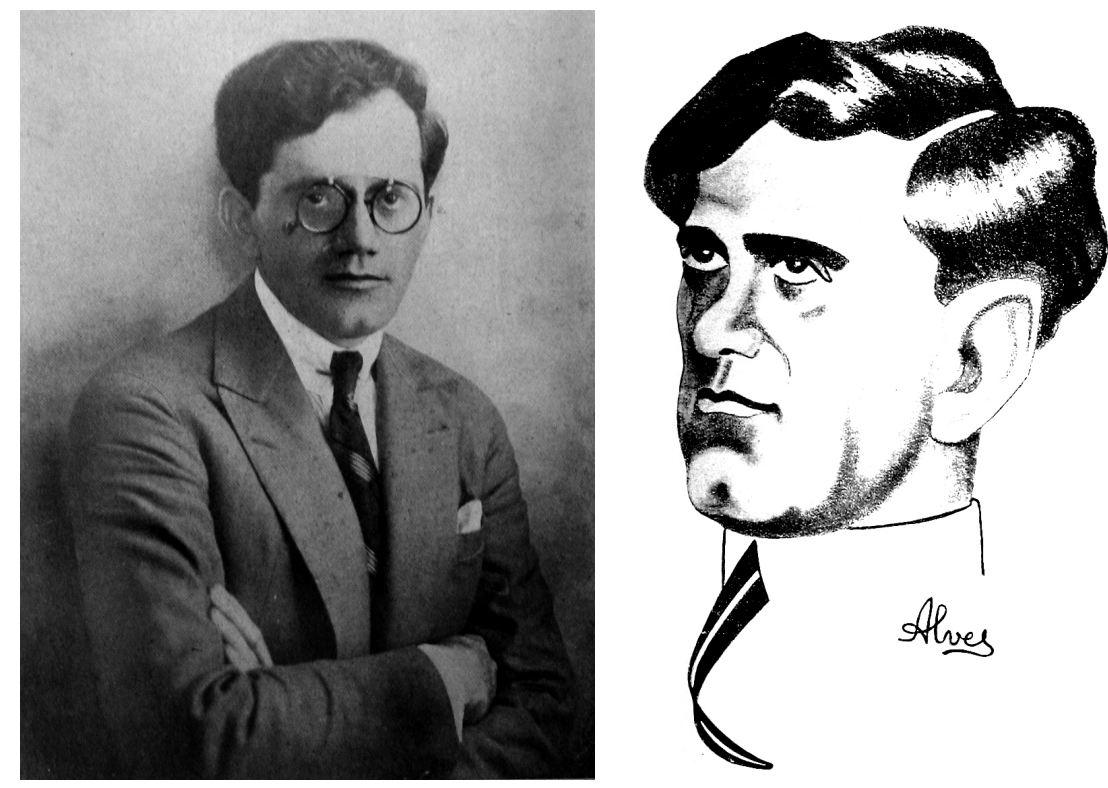

Figuras 1 e 2: Fotografia e charge de Nestor de Figueiredo de 1927 e 1930, respectivamente(Fontes: Angyone Costa, 1927 e revista Architectura e Construcções, n.7, v. 1, fev. 1930)

Vistas assim, essas e outras passagens soltas, significativas, apesar de insuficientes, funcionam indiciandoalgumas dasvertentes de trabalho e âmbitos de intervenção caros a Nestor de Figueiredo ainda à espera de investigações mais consequentes a respeito: o alinhamento à causa de uma arquitetura com expressão nacional, que o levaria do Rio às cidades históricas de Minas em viagem de estudo a soldo de Marianno Filho; o exercício prático de projeto, do edifício isolado à escala da cidade e do urbanismo, etc.; uma inserção constante no debate público acerca da arquitetura, do urbanismo e do seu exercício no Brasil através da colaboração na imprensa diária e em periódicos especializados como Arquitetura e Urbanismo, Urbanismo e Viação e Arquitetura e Construções, Arquitetura no Brasil, entre outros.

Atravessando essas frentes diversas de intervenção e conferindo-Ihes mais sentido, está o prolongado engajamento emórgãos de representação de classe, tendo Figueiredoocupado a presidência do Instituto Central de Arquitetos entre 1930 e 1932 e, com a reforma deste, do Instituto de Arquitetos do Brasil (IAB), de 1936 a 1943. Pelos vínculos de classe, esteve à frente diversas vezes de comissões nas participações em eventos dentro e fora do Brasil, como os Congressos PanAmericanos de Arquitetos de 1927, 1930 e 1940, além de representar os institutos em URBANA, V.5, no6, mar.2013 - Dossiê: Urbanistas e Urbanismo- CIEC/UNICAMP 
vários concursos, como o do Farol de Colombo, cuja final, em 1931 no Rio de Janeiro, contou com a presença de Frank Lloyd Wright e ElieelSaarinen (SANTOS, 1977).

Sem a intenção de abarcar tal variado escopo de interesses, e alinhado à temática do evento, este texto atém-se a investigar as proposições no campo do urbanismo que Figueiredo passa a elaborar a partir do trabalho de remodelação urbana para o Recife apresentado durante o IV Congresso Pan-Americano de Arquitetos, realizado no Rio de Janeiro em 1930, ganhador, na ocasião, do prêmiohonra do júri internacional.No que diz respeito à faceta de urbanista de Figueiredo, é a essa proposta e sua repercussão imediata, com o consequente convite do prefeito Lauro Borba para que ele levasse adiante a elaboração de um plano urbanístico para a capital pernambucana, queremetea quase totalidade das referências historiográficas, como se constituísse uma experiência isolada e excepcional (OUTTES, 1997; PONTUAL, 1995).

Entretanto, diferente do que se pode deduzirda historiografia corrente, o plano para Recife representou tão somente a parada inicialda verdadeira "peregrinação" de Nestor de Figueiredo pelo Nordeste ao longo da década de 1930, convertido numa espécie de "arquiteto-urbanista andarilho", percorrendo capitais e cidades do interior dos estados nordestinos elaborando projetos de arquitetura e de intervenção, de expansão, remodelação e criação de cidades novas na região.O que o levaria, num espaço de pouco menos de cinco anos, a propor planos ou apenas ser sondado para desenvolver serviços de urbanismo em Recife e Olinda (PE), em João Pessoa, Cabedelo e Campina Grande (PB), Fortaleza (CE), Teresina (PI), além do traçado de duas estâncias termais, Brejo das Freiras, no sertão paraibano, e Salgado, em Sergipe.

Embora poucas dessas iniciativas chegassem de fato a se concretizar, com algumas não passando de demonstrações de interesse fugaz por parte das autoridadespúblicas, as premissas, instrumentos legaisde planejamento e os arranjos formais presentes nos planos deixam transparecera compreensão e manejo do cabedal teórico e projetual-subjacente à emergente cultura urbanística no país desde os anos 1920 e em expansão nas décadas seguintes, manifestano aumento considerável do número de projetos de reforma ouexpansão urbanae criação de cidades novasno Brasil afora, num crescendo que culminariano concurso para o plano piloto de Brasília.De meados dos anos 1920 ao final da década seguinte, Rio de Janeiro, São Paulo, Belo Horizonte, Vitória, Niterói, Porto Alegre, Recife, Fortaleza e João Pessoa, entre outras cidades, seriam objeto de planos de conjunto ou de URBANA, V.5, nº6, mar.2013 - Dossiê: Urbanistas e Urbanismo- CIEC/UNICAMP 
intervenções pontuais, de reforma, embelezamento ou expansão envolvendo profissionais da engenharia e da arquitetura, brasileiros e estrangeiros, como Agache, Prestes Maia, Atílio Correia Lima, Armando de Godoy, Lincoln Continentino, Arnaldo Gladosch e Nestor de Figueiredo (LEME, 1999).

Das muitas iniciativas empreendidas por Figueiredo no decurso de seu périplo nordestino, o caso de Recifeconcentra a atenção da historiografia, sem maiores menções aos demais projetos. Tendo em vista essa situação,este artigo desenvolvese, sobretudo, em torno do plano concebido para a cidade de João Pessoa, conduzido simultaneamenteàquele para o Recife e o único dos projetos a se implantar de fato, para a surpresa do próprio urbanista.

Sem desconsiderar que este plano compõe um conjunto de maior envergadura com os demais elaborados no Nordeste, com o qual compartilha não poucas afinidades e semelhanças em termos de procedimentos metodológicos e soluções de desenho urbano, a abordagem aqui adotada privilegia a identificação e discussão de paralelos, aproximações e contrapontos no interior desse conjunto e,de modo semelhante,tece relações com a cultura urbanística contemporânea à busca das basesdo pensamento de Nestor de Figueiredo no que tange ao urbanismo. A intenção é mostrar como Figueiredo é ao mesmo tempo tributário e partícipe da cultura urbanística em formação no Brasil, atravessada por não poucas ideias e práticas do urbanismo internacional que por meios diversos aportava no país, adensando o debate acerca da cidade brasileira e seu futuro,tão candente nesse momento.

\section{Do edifício à cidade, da arquitetura ao urbanismo}

É tardio e algo surpreendente o engajamento de Nestor de Figueiredo ao urbanismo quando comparado à diligente atividade de arquiteto de edifícios, públicos e privados, encetada tão logo se estabelece no ofício. Seus escritos da década de 1920, divulgados em jornais diários e revistas especializadas, em quase nada indiciam esse desdobramento de atribuição profissional. O capital simbólico amealhado até o momento da entrevista a Angyone Costa, suficiente para justificar sua presença entre os selecionados para o inquérito, advinha praticamente dos compromissos com a causa neocolonial e da determinante participação em instituições de classe. De modo que a explicação para essa ampliação do escopo profissional talvez esteja nas circunstâncias por demais propícias à reflexão e ao debate sobre a cidade e as questões urbanísticas em curso no final dos anos 1920, com especial intensidade 
naquele espaço representativo por excelência dos destinos da nação, a cidade do Rio de Janeiro, capital federal.

Já evidenciando as imbricações entre arquitetura, nação e formação nacional e seu rebatimento nas considerações sobre a natureza "brasileira" das nossas cidades, as polêmicas suscitadas acerca da necessidade de um plano urbanístico para a capital, de forma a dotá-la de credenciais condizentes com as aspirações de modernidade cultivadas pelas elites dirigentes e setores intelectuais, sem descurar de sua condição modelar de fulcro da identidade nacional, acabariam por levar, sem qualquer consenso estabelecido,à contratação do urbanista francês Donat Alfred Agache em 1927 (REZENDE, 1982; BRUANT, 1996; MOREIRA, 2007:95-114).

Alinhado na defesa da vinda de Agache, Nestor de Figueiredo comparece entre os arquitetos brasileiros que se tornariam assistentes do urbanista francês (CAMPOS, 2002), atuando sob sua orientação no desenvolvimento dos trabalhos do plano de remodelação, extensão e embelezamento do Rio de Janeiro, concluído e publicado em 1930. Ainda que não se possa afirmar com convicção a presença de Figueiredo entre os assistentes diretos de Agache, não seria estranho que uma proximidade estreita houvesse se estabelecido entre eles, seja por vias institucionais, através do Instituto Central de Arquitetos (ICA), de cuja diretoria o brasileiro amiúde tomava parte, seja pela mediação de José Marianno Filho, que recepcionou Agache no canteiro de obras do Solar do Monjope, na lagoa Rodrigo de Freitas (A NOITE, 07/07/1927).

A despeito disso, fato é que as ressonâncias do urbanismo de Agache percebem-se no primeiro ensaio nessa nova seara profissional de Figueiredo, com a proposta de remodelação do Recife exposta durante o IV Congresso Pan-Americano de Arquitetos, em 1930. Certamente que não apenas da obra de Agache em si, comoda cultura urbanística relacionada à Sociéte Française des Urbanistes (SFU),cuja síntese teórico-formal apresenta-se condensada em suas concepções.

Fundada em 1913 e reunindo entre seus membros Eugène Hénard, J. C. N, Forestier, Léon Jaussely, Henri Prost, além de Agache, entre outros, aSociéte Française des Urbanistes funcionava como uma espécie de grande laboratório de urbanismo, com seus integrantes concebendo planos urbanísticos para inúmeras cidades, na França, especialmente após a lei Cornudet, nas colônias francesas e em várias outras cidades de diversos países, como Camberra, Guayaquil e Rio de Janeiro, afinados com o objetivo de "estudar, em conjunto, tudo o que diz respeito ao futuro das cidades" (BRUANT, 1996:168). 
A articulação entre forma urbana e arquitetura, utilizando-se do traçado das vias, da tipologia dos edifícios, de praças, obeliscos e monumentos como elementos de composição estética, tratando urbanismo e arquitetura, plano e projeto como momentos indissociáveis de um únicoprocesso de desenho da cidade, aspectos que perpassam as soluções desenvolvidas por Agache para o Rio de Janeiro encontram acolhida e repercutem na proposição de Figueiredo para Recife.

Aí, a aplicaçãodo zoning como instrumento de agenciamento funcional da cidade atrela-se a um sistema viário radial-perimetral, adotadopor Agache no Rio,definindo uma rede de conexões articuladas em alguns nós de distribuição dos fluxos que ligam a área central aos diversos bairros, num esquema que seria recorrente tanto em João Pessoa como no estudo preliminar elaborado para Fortaleza, em 1933.Em Recife, um dos principais e estratégicos eixos de distribuição do tráfego urbano é a Praça da Independência, marco simbólico da nova imagem da capital pernambucana que o plano de Figueiredo pretendia moldar (OUTTES, 1997).

No zoneamento prevê-se a transformação dos bairros do Recife e de Santo Antonio em "bairros de grandes negócios", ficando aquele com o comércio grossista e negócios bancários e o último reservado ao comércio de luxo. Também para o bairro de Santo Antonio é apresentada uma legislação que estabelece as normas de construção e de compra e venda de terrenos, semelhante ao utilizado no Rio de Janeiro quando do desmonte do Morro do Castelo.

Figueiredo concebe zonas residenciais de três tipos, cada uma delas regida por uma legislação urbanística que determina parâmetros específicos de ocupação dos lotes e de construção. A zona principal, mais próxima da área comercial da cidade, os bairros jardins, que abrangem os arrabaldes despovoados e para os quais recomenda o uso de grandes áreas verdes e a zona rural, ocupando a periferia da cidade. Além dessas, o plano prevê ainda uma zona industrial, cuja localização seria determinada pela proximidade com a estrada de ferro e pela proteção de outras áreas da cidade contra a poluição das fábricas, e um bairro universitário nos arredores do Jardim 13 de Maio, ideia derivada de proposta semelhante a desenvolvida por Agache, e presente também no plano para a capital paraibana 


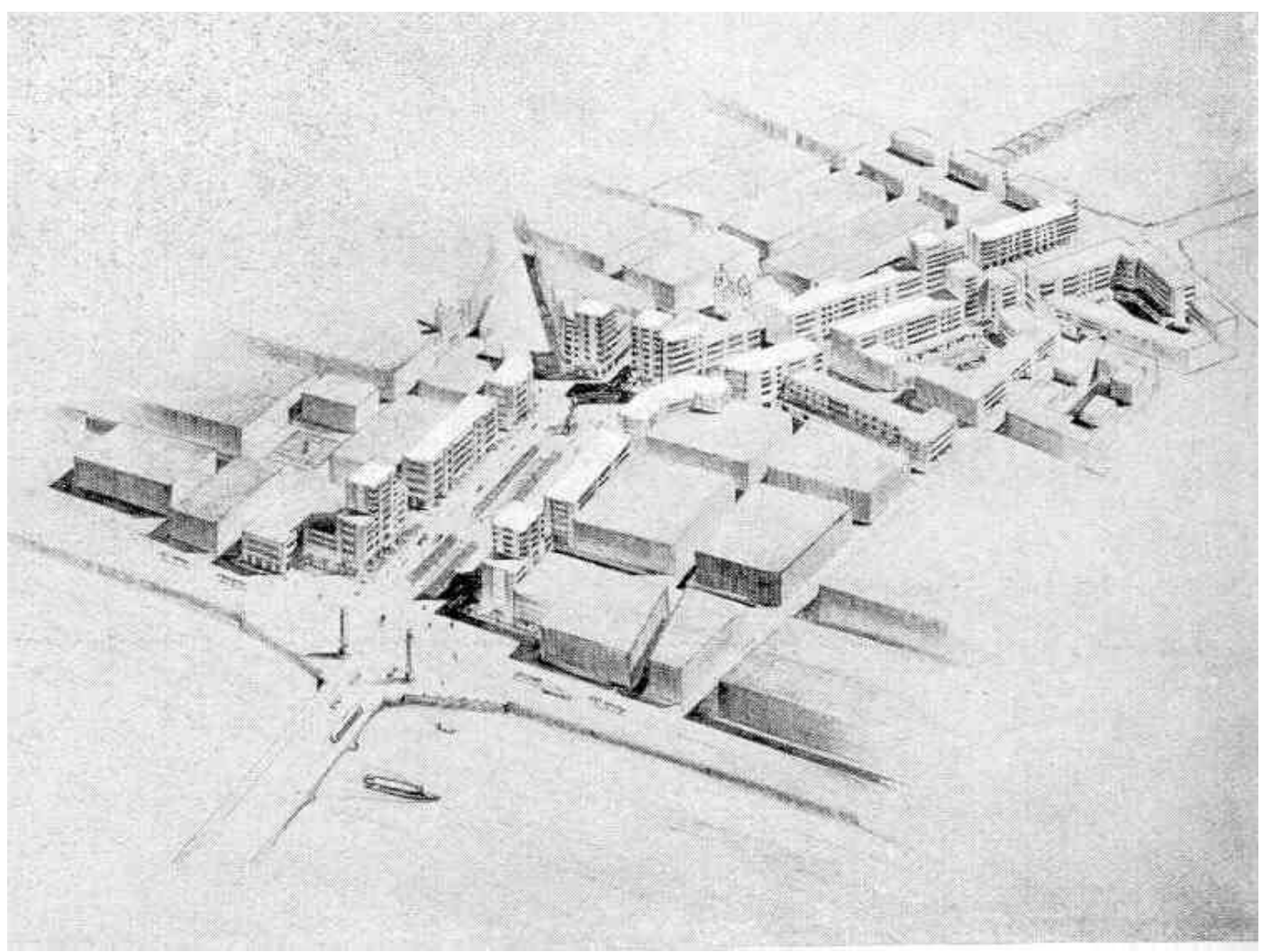

Figura 3: Uma das perspectivas do plano de remodelação de Recife apresentado por Nestor de Figueiredo em 1930 (Fonte: Arquitetura e Urbanismo, n.2, mar./abr. 1940)

Concomitante às negociações envolvendo as propostas para o Recife, razão pela qual guarda inúmeras afinidades e características em comum, o plano para João Pessoa destoa por completo daquele quanto à polêmica em que se viu envolvido o urbanista num ambiente de tão intenso debate sobre a cidade e o urbanismo como é Recife nos anos 1920 e 1930, onde as opiniões de um José Estelita, por exemplo, eram defendidas a partir de um arsenal teórico sacado diretamente das discussões mais atuais do campo do urbanismo no Brasil e no exterior.

Talvez isso explique o fato curioso de que, embora chamado inicialmente para Recife, já nas primeiras viagens para estudar in loco aspectos pertinentes a este plano, Nestor de Figueiredo seja convidado pelo interventor paraibano Anthenor Navarro para levar adiante projeto similar na Paraíba, conferindo-Ihe prioridade, conforme breve nota no jornal A Província, de maio de 1932: "o sr. Nestor de Figueiredo vai primeiro à Paraíba, onde dará início aos anteprojetos de Cabedelo e João Pessoa. Só depois de terminados estes serviços é que [...] atacará o estudo da remodelação do Recife"(A PROVÍNCIA, 07/05/1932). 


\section{Porto, cidade e plano}

De saída atrelado às obras de modernização da estrutura do porto da vila de Cabedelo - motivo de sua inclusão no bojo do plano para a capital paraibana -e compreendido, portanto, em meio às "grandes realizações do governo revolucionário na Paraíba"(A UNIÃO, 07/009/1933), o plano de desenvolvimento sistemático da cidade de João Pessoa e da vila de Cabedelo, como foi inicialmente divulgado pela imprensa, teve sua origem diretamente atrelada ao par porto/capital, em cuja imbricação deveria operar, assumindo de antemão como uma de suas premissas justamente a de promover a interação entre esses espaços, reconhecendo as implicações funcionais do movimento portuário sobre a estrutura da capital.

Conforme os termos em que se firmou o contrato entre o governo paraibano e Nestor de Figueiredo, através do decreto n. ${ }^{\circ}$ 261, de 9 de março de 1932, para estudo e proposição de um plano de remodelação e extensão para João Pessoa caberia a ele "tanto pelo lado estético como pelo aspecto econômico, de higienização e estilo [fixar] uma orientação metódica e segura e acompanhar o seu desenvolvimento de modo racional e de acordo com as exigências modernas", com a incorporação da vila de Cabedelo impondo-se "como obra complementar à de construção de seu porto" (PARAÍBA, 1932: 18).

As circunstâncias da vinda em 1932 de Nestor de Figueiredo caracterizaram-se por uma combinação danosa em termos urbanísticos, entre crescimento urbano acelerado, porém, desprovido de normativas de disciplinamento da expansão em curso, e uma patente limitação dos serviços públicos em corresponder a tal crescimento. De um lado, a constatação oficial do caráter excepcional dos serviços de abastecimento d'água e esgoto, de outro, a denúncia pelo médico Josa Magalhães, da Sociedade de Medicina e Cirurgia, da permanência do "à vontade" na construção da capital, cuja mancha urbana estendia-se antes orientada pelos interesses dos proprietários de terrenos do que por qualquer diretriz de planejamento traçada pelo poder público, que para efeitos de disciplinamento das construções valia-se apenas do Código de Posturas Municipais de 1928, que no aspecto urbanístico propriamente dito limitava-se a distinguir entre os perímetros urbano e suburbano da cidade.

É a cidade resultado do primeiro ciclo de reformas urbanas dos anos 1910 e 1920 que percebe Nestor de Figueiredo ao sobrevoá-la tão logo chega em sua primeira visita, tomando vários registros fotográficos, alguns dos quais ilustrariam a entrevista concedida para $A$ União. Recurso indispensável ao planejamento que era o 
avião, ressaltava Figueiredo, fora favorecer a "organização de um plano cadastral pelo sistema aero-fotográfico", permite uma leitura abrangente da estrutura urbana, possibilitando ao urbanista "surpreender a cidade em plena vibração", que assim vê às claras o organismo urbano em funcionamento, com seus fluxos e atividades observados sem intermediações, do mesmo modo "os vários fenômenos que concorrem para o seu desenvolvimento irregular ou desordenado"(A UNIÃO, 04/02/1932).

É assim que desde cima Figueiredo nota que "na parte central e na periferia construções novas são erguidas e novas ruas vão sendo abertas para receber futuras edificações" (Idem), percebendo o crescimento da capital mais determinado para o sul, seguindo a estrada para o Recife, nos bairros de Jaguaribe e Cruz das Armas, onde se acomodava o grosso da população operária da cidade, e cujas ruas, se estendendo para além do mais aristocrático Trincheiras, se confundiam aqui e ali com o entorno rural. De certo veria também a ocupação ao leste, nas adjacências da praça da Independência, que assim como a avenida João Machado, concentrava os palacetes da burguesia local.

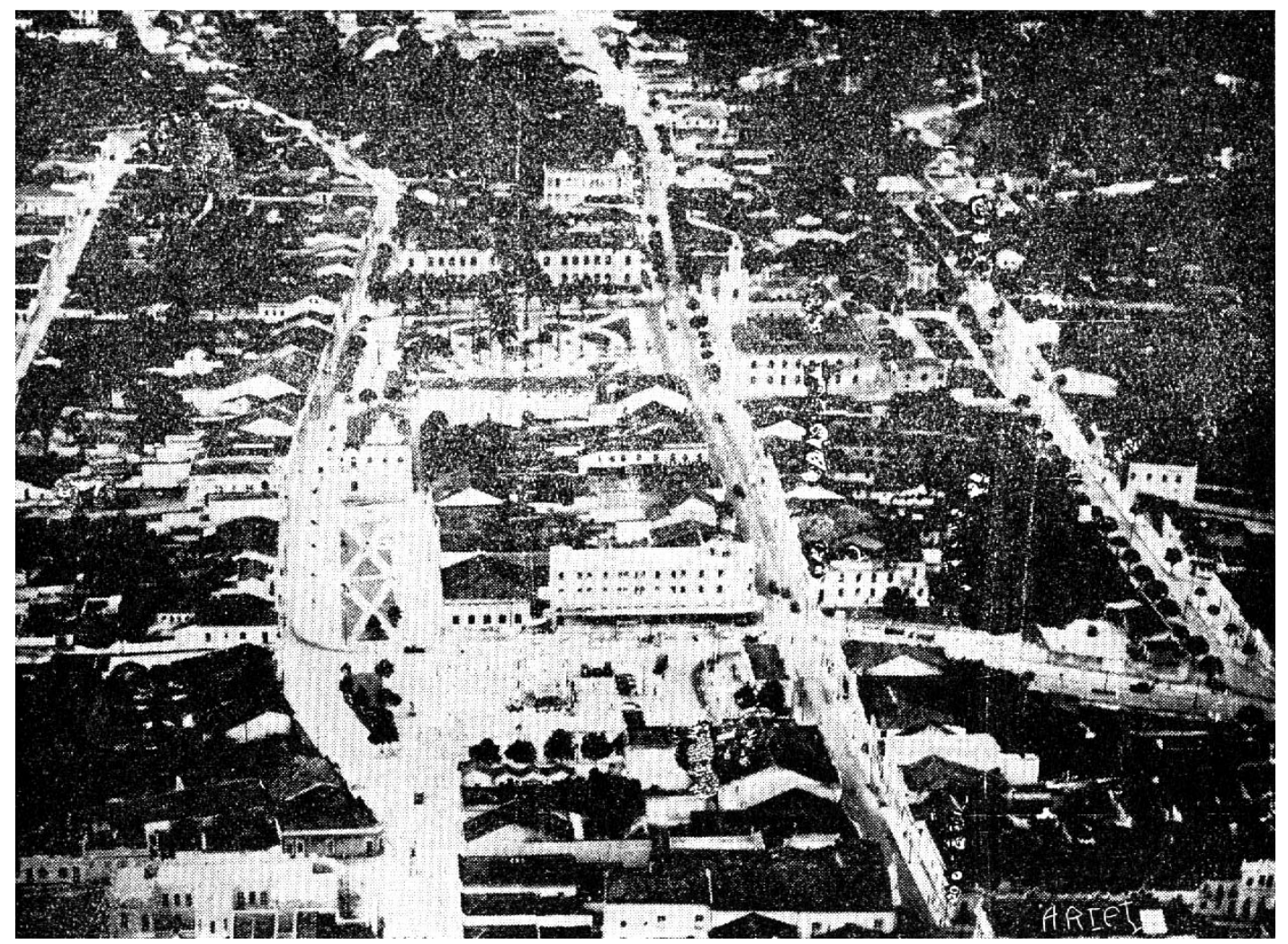

Figura 4: Vista aérea do centro de João Pessoa tomada do levantamento feito por Nestor de Figueiredo (Fonte: Almanach do Estado da Parahyba, 1932) 
Mais do que perceber tendências de crescimento, Figueiredo deve ter observado também certa especialização funcional nalgumas áreas da cidade, na verdade historicamente constituída e não devida a qualquer normativa de uso, a não ser aquelas decorrentes de critérios higienistas recomendando a instalação de um ou outro equipamento em determinados pontos da estrutura urbana: a concentração de atividades comerciais nas imediações do ancoradouro do Sanhauá e em logradouros que faziam a ligação entre a Cidade Baixa e a Alta, em particular nos arredores da rua Maciel Pinheiro; a disposição em número considerável de instalações hospitalares um pouco ao sul da avenida João Machado, mais ou menos no ponto em que esta encontrava a avenida Maximiano de Figueiredo, que vinha desde a praça da Independência; a concentração de camadas populares no Varadouro, no Roggers, ao norte, e naqueles bairros de Jaguaribe e Cruz das Armas, e as classes mais abastadas acomodando-se pelas Trincheiras e Tambiá.

Segundo Figueiredo, falando para A União, órgão oficial do estado, embora certo bom senso tivesse orientado as ações técnicas na construção da cidade, de "um pitoresco tão acentuado dentro de seu conjunto regional inconfundível", faltava a ela "o plano coordenador que unificasse o ritmo e realizasse a obra de conjunto que deve ser o plano de uma cidade" (Idem). Se aquelas se consubstanciaram como ações isoladas e dispersas no tecido urbano, em intervenções de caráter pontual, conforme a lógica que orientou as reformas e melhoramentos urbanos conduzidos nas cidades brasileiras entre as últimas décadas do século XIX e as primeiras do XX, Figueiredo assim situando seu plano, parece reclamar para ele, nascido de uma compreensão abrangente da cidade, suas atividades e fluxos, a condição de instrumento capaz de gerir o planejamento do todo urbano.

Assentado em critérios de eficiência funcional e rentabilidade financeira, atendo-se às necessidades econômicas, de higiene urbana, de tráfego sem, contudo, descurar da regularização das edificações e das questões de estética urbana, o plano sendo "uma medida de disciplina em benefício da coletividade", constitui também "uma fonte de estímulo para a população que poderá inverter com segurança o seu capital em edificações porque sabe, antecipadamente, o que será a cidade futura"(A UNIÃO, 04/02/1932). Como diria o mesmo Figueiredo, falando desde o Recife, "devemos de começo declarar que nenhum plano de remodelação de cidade é traçado sem objetivo econômico", e se ele de imediato implica em dispêndio, "a sua finalidade econômica resultará posteriormente pelo aumento progressivo dos valores urbanos e pela defesa dos prejuízos resultantes do desenvolvimento desordenado das cidades 
construídas ao acaso" (apud PONTUAL, 1995:803). Para isso, o urbanista, separando usos e organizando funcionalmente a cidade e sua expansão, elimina fatores nocivos ao capital imobiliário aplicado, salvaguardando dessa forma o valor da propriedade, tal como pensara Agache no seu plano para o Rio de Janeiro em 1930(REZENDE, 1982:80).

Mas se eram esses os parâmetros a nortear o plano de uma cidade, esse processo, todavia, não prescinde da preservação de suas peculiaridades, da sua personalidade mesma, nem implica na perda do seu "pitoresco", cujo aproveitamento, por outro lado, não deve "perturbar as grandes composições de massa edificadas que a sua evolução futura exigirá". Desse modo, para Figueiredo, "toda a dificuldade estará no senso do equilíbrio"(A UNIÃO, 04/02/1932): conciliar o conjunto das necessidades de uma cidade moderna consubstanciadas no plano com a permanência e mesmo incorporação de valores tradicionais, paisagísticos, históricos e naturais da cidade, a serem potencializados dentro da concepção urbanística. Tal premissa talvez repercuta a defesa da fisionomia arquitetônica do Nordeste propugnada pelo Centro Regionalista do Recife e o conteúdo dos debates travados no congresso organizado pelo centro em 1926, do qual Figueiredo participou como representante do Instituto Central de Arquitetos.

Uma das primeiras medidas tomadas, antecedendo a própria assinatura do contrato com o urbanista, foi a constituição de uma comissão do plano da cidade, da mesma forma que se dera no Rio de Janeiro e no Recife. Instrumento peculiar ao urbanismo norte-americano, espaço de representatividade dos interesses públicos e privados, das diversas classes e segmentos sociais, reunindo os agentes de algum modo preocupados com a cidade, à comissão do plano da cidade caberia auxiliar o urbanista acompanhando a elaboração do plano e fornecendo informações sobre questões específicas e, concluída essa etapa, zelar pela implantação da proposta conforme traçada(A UNIÃO, 09/03/1932).

Com pouco mais de um mês de trabalho, auxiliado por uma equipe constituída por Leonidas Vargas Dantas, Hélio Duarte, Dante Jorge de Albuquerque e EddyFriedmann(A UNIÃO, 08/05/1932), Figueiredo apresenta uma primeira versão do plano, com duas plantas referentes à capital e à vila de Cabedelo, que não seriam alteradas de forma substancial, apenas melhor esmiuçadas, em outubro, quando ele aparece de modo praticamente definitivo.

No tocante à vila de Cabedelo, ainda que considerando os efeitos da modernização do porto sobre sua estrutura urbana, sobressaí uma orientação que não URBANA, V.5, n6, mar.2013 - Dossiê: Urbanistas e Urbanismo- CIEC/UNICAMP 
se prende apenas ao atendimento das exigências funcionais, revelando antes uma preocupação com a estética urbana, com a definição de um eixo central através de uma parkway conectando os dois centros propostos, um de distribuição e outro administrativo, entre os quais se estende a zona residencial chegando à orla na forma de bairros balneários "projetados dentro das linhas curvas que a sinuosidade da natureza indica" (Idem). Além de indicar a necessidade de operações corretivas no traçado existente, a mais contundente sendo a que sugere o deslocamento da estação da Great Western e a transformação do leito das linhas férreas numa avenida voltada ao comércio varejista, Figueiredo também apresenta um projeto para ampliação do porto a ser apreciado por técnicos especialistas no assunto. Em conjunto, o que prevalece no caso de Cabedelo são medidas voltadas a sua transformação numa espécie de "sala de visita" da capital, nelas ficando subsumidas as questões funcionais decorrentes do porto, como bem notaria o médico Flávio Maroja em artigo publicado n'AUnião quanto à função assumida por essa vila no conjunto urbanístico então delineado(A UNIÃO, 30/08/1932).

No plano para a capital, Figueiredo adota duas posturas distintas no trato do que denominou "cidade existente", ou seja, a área urbana construída à época e que fora objeto de intervenções nas duas décadas anteriores; e "cidade futura", a vasta zona de expansão urbana no quadrante leste-sul da cidade que concentra as maiores atenções do urbanista. Articulando essas duas "cidades", um sistema viário cujo desenho deriva em parte das necessidades funcionais decorrentes do porto, cujos fluxos para aí se dirigindo ou daí procedendo, cruzavam o espaço da capital.

Com intervenções pontuais articuladas e de impacto limitado na estrutura urbana existente, tanto por razões financeiras, de modo a reduzir os custos na implantação do plano, como por questões mais subjetivas, de reconhecimento dos seus valores históricos intrínsecos, para a "cidade existente" o plano propõe a ampliação das comunicações entre a Cidade Alta e o Varadouro e a criação de um bairro comercial separado em comércio grossista e varejista e de um setor para equipamentos industriais, todos nas proximidades do ancoradouro do Varadouro, subindo por algumas ruas, como a Maciel Pinheiro, num zoning que pouco faz além de ratificar usos historicamente associados a essa área da capital. Em conformidade com aquele primeiro propósito, o plano indica a retificação do trajeto da rua Barão do Triunfo, já alargada com sua transformação em uma avenida de acesso ao porto em princípios da década de 1920, de modo a orientar seu percurso em direção à área de comércio grossista, mais próxima ao rio Sanhauá, desviando-a do curso normal para a 
rua Maciel Pinheiro, onde se concentrava o comércio varejista. Com semelhante fim é tomada a rua Padre Azevedo que subindo quase em paralelo à Barão do Triunfo, a encontraria na altura da Praça Pedro Américo, daí prosseguindo pela rua Guedes Pereira até atingir a Praça Vidal de Negreiros.

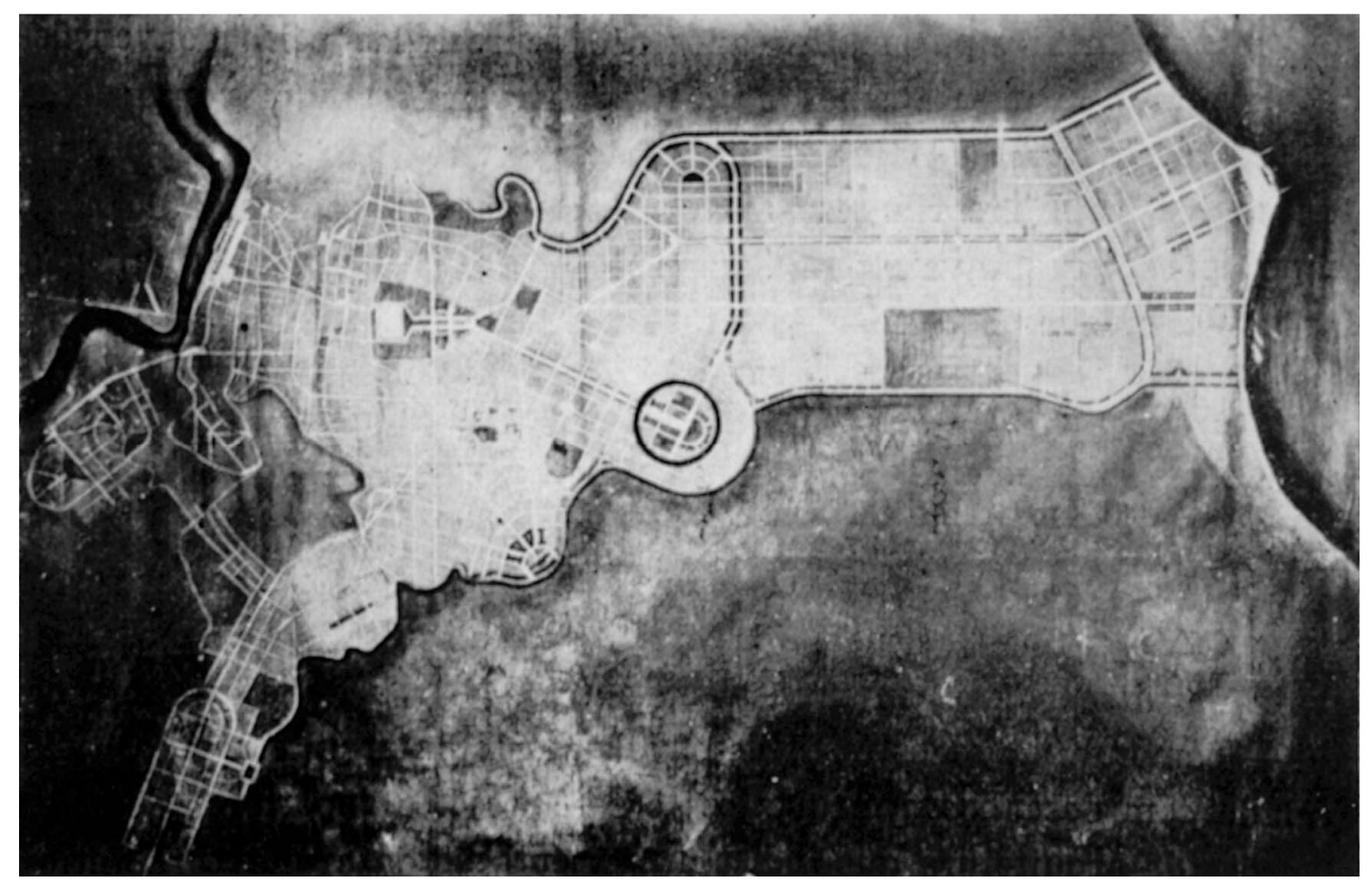

Figura 5: Plano de remodelação e extensão de João Pessoa apresentado por Nestor de Figueiredo em 1932; o Centro Cívico aparece delimitado pelo círculo (Fonte: Base, 1933)

A intervenção mais incisiva na "cidade existente" decorre da intenção de "corrigir o aspecto defeituoso e pouco atraente que oferece a entrada da cidade, pela estrada que vem do interior"(A UNIÃO, 10/03/1932), e se manifesta no entorno da Estação da Great Western, na área do Varadouro junto ao rio Sanhauá. Nesse ponto o plano recomenda a substituição de toda essa parte da cidade, com o deslocamento da estação existente para um local mais próximo à ponte que dava para a estrada que ligava a capital ao interior, onde já se encontravam edificações industriais, de forma que aproveitando uma vasta extensão de terrenos devolutos fosse criada uma Praça de Desembarque para a nova estação junto a uma esplanada que se desenvolveria paralela ao rio, assim incorporado à paisagem urbana(A UNIÃO, 02/05/1932). Bem ao modo das "portas", "entradas" e "salas de visita", numa praxe corrente em planos de remodelação nos anos vinte e trinta, como é o caso da "Porta do Brasil", de Cortez e Bruhns para o Rio de Janeiro, em 1925-1926, que reapareceria em tudo semelhante na "Entrada do Brasil" concebida por Agache para a capital federal ou a transformação 
do vale do Anhangabaú na "Sala de Visitas para São Paulo" no Plano de Avenidas de Prestes Maia (TOLEDO, 1996: 270-274).

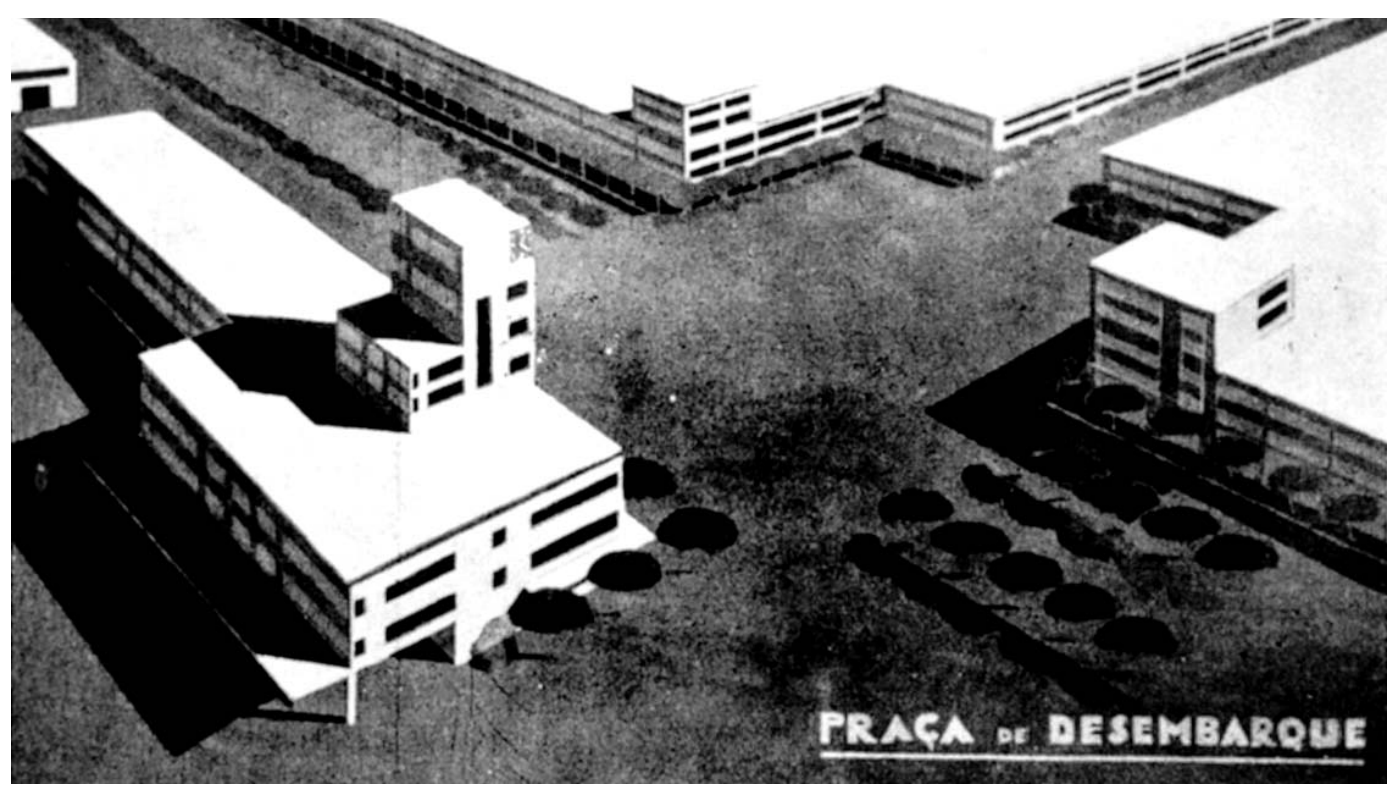

Figura 6: A Praça de Desembarque, a nova "porta de entrada" da capital paraibana (Fonte: Base, 1933)

Espaço monumental de caráter simbólico de recepção na cidade, cujo equivalente no plano para Recife se configura na Praça da Independência, caberia à Praça do Desembarque, assim como àquelas "portas" e "salas de visitas", transmitir uma impressão da cidade a partir da percepção de fragmentos urbanos significativos, já que em matéria de urbanismo "as primeiras impressões também são consideradas como fator psicológico de grande importância, e por isso são apreciadas no sentido de torná-las agradáveis a quem, de fora, se vem pôr em contato com uma cidade ainda não conhecida"(A UNIÃO, 10/03/1932).

\section{A cidade futura, do rio ao mar}

No planejamento da zona de expansão urbana, um aspecto primeiro considerado por Figueiredo foi o do local em que se implantaria o que chamou de "centro de irradiação" ou "centro de distribuição da cidade futura", do que dependeria a forma como iria se desenvolver o conjunto urbano. No entanto, o que segundo ele demandaria um estudo minucioso e acurado, a escolha do local para assumir tal função aparecia então praticamente definido pela própria configuração do desenho resultante do crescimento da capital nas últimas décadas, que indicava como opção quase natural o Parque Solon de Lucena, como percebera Saturnino de Brito em seu plano de 1913 ao considerar a lagoa como cabeça-de-ponte do plano de extensão que 
propõe para a cidade, baseado em quarteirões triangulares segundo um traçado sanitário que seria completamente desconsiderado em favor de "alinhamentos retos, em xadrez" (BRITO, 1943:374) quando foram estiradas as primeiras ruas para aqueles lados, ainda na década de 1910.

Mas o que na ocasião do plano de Brito era um largo trecho de matagal abandonado, cuja aparência não destoaria muito disso mesmo após sua transformação num parque urbano entre as obras do prefeito Guedes Pereira, em princípios dos anos 1930 dava mostras de uma ocupação mais sistemática pelos empreendimentos imobiliários do Montepio dos Funcionários Públicos do estado, proprietário de terrenos na área e que nela promoveria ao longo da década a construção de casas para seus contribuintes, numa primeira investida no setor habitacional na capital(A UNIÃO, 07/02/1932).

Espaço de passagem e elemento de articulação da "cidade existente" com a "cidade futura", o Parque Solon de Lucena como "centro de irradiação" seria o ponto de origem da nova estrutura viária da capital definida a partir de um sistema de parkways, que em si constituía a ossatura do plano na zona de expansão, cuja superfície projetada era várias vezes superior à da cidade existente. Estendendo a área urbana do sul, desde Cruz das Armas, ao leste, incorporando definitivamente Tambaú - então um recanto de veraneio e vila de pescadores - à capital, o plano rompe de vez os limites em que ela se mantivera por mais de três séculos, relutante em transpor a lagoa que Ihe obrigava a um crescimento irregular.

Como "centro da cidade futura"(A UNIÃO, 10/03/1932), o Parque Solon de Lucena abrigaria um dos "conjuntos ideais de edificação", conforme chama Figueiredo os conjuntos arquitetônicos com funções especializadas que propõe - de modo semelhante ao que Agache fizera no seu plano para o Rio de Janeiro (REZENDE, 1982:80-81) - articulados em sua disposição aos percursos das parkways projetadas. É assim que nesse local e margeando a parkway que se desenvolvia em concordância com a Praça Vidal de Negreiros e contornava o espelho d'água da lagoa - que por isso passaria a ser conhecida vulgarmente como parkway da lagoa - daí prosseguindo por entre terrenos pertencentes ao Montepio, se implanta o Centro de Administração Municipal, numa localização determinada por sua maior proximidade com a área urbana, facilitando assim o acesso da população às instâncias administrativas do governo da cidade. 


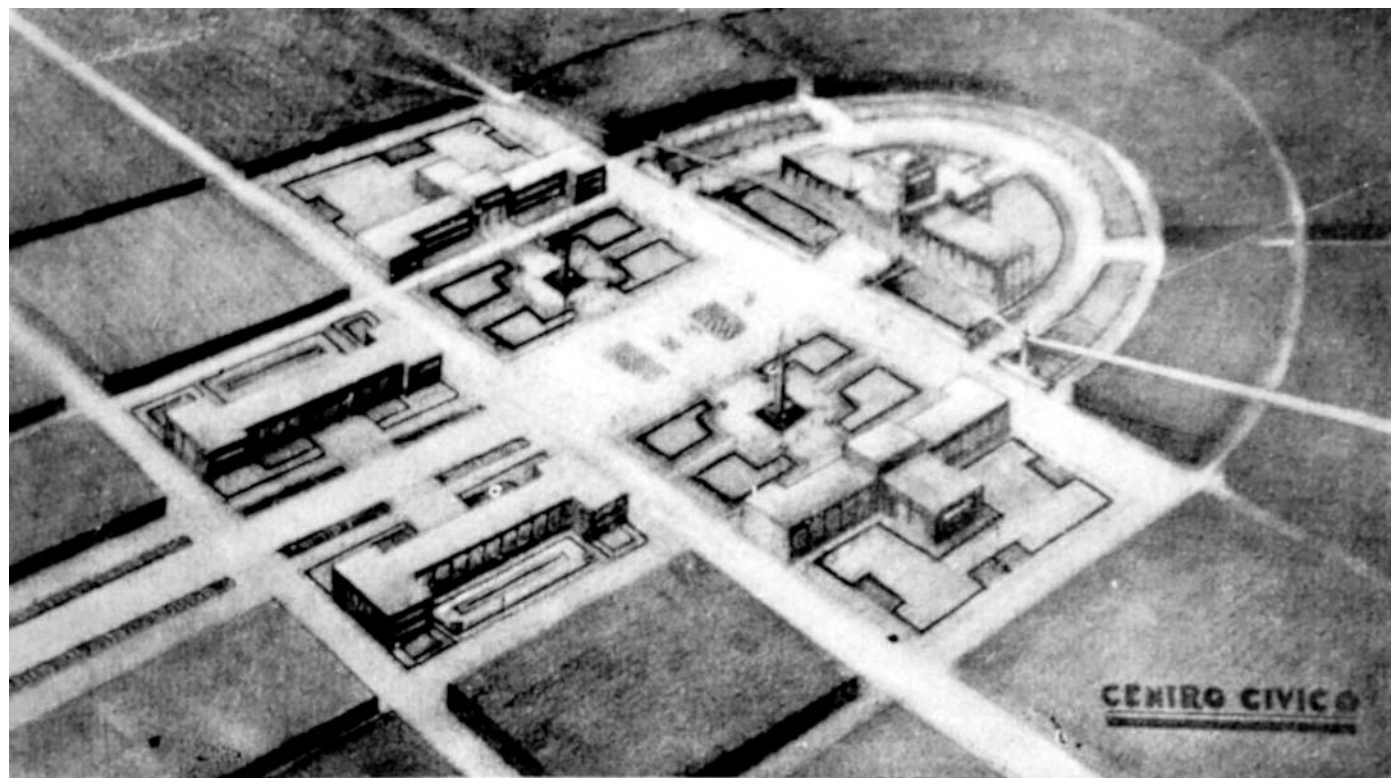

Figura 7: Centro Cívico da "cidade futura", implantado na extremidade da principal parkway da área de expansão da capital paraibana (Fonte: Base, 1933)

Num dos braços em que se bifurca essa parkway estariam mais dos centros, o Universitário - na extremidade dessa avenida e funcionando também como espaço de irradiação de novas vias - e o Bairro da Saúde, naquela área da capital em que já estavam a Maternidade e o Hospital de Isolamento, numa tendência de uso que Figueiredo apenas acentua. Um último centro e o de feição mais monumental no arranjo urbanístico, por sua implantação na extremidade da maior parkway - traçada no rumo da região de Cruz do Peixe e aproveitando o eixo da existente avenida das Missões - seria o Centro Cívico destinado à administração estadual No ponto de convergência da perspectiva dessa avenida-parque, Figueiredo dispõe um conjunto arquitetônico simétrico com espaços livres, jardins e obeliscos em que sobressaí o edifício do governo do estado, encimado por uma cúpula, a partir do qual partiriam diversas vias radiais, conformando o elemento mais característico da proposta num desenho que remete à da zona administrativa que Attílio Corrêa Lima conceberia para Goiânia em 1933 (LEME, 1999:226).

Deve-se considerar no caso desses conjuntos de edificações, é que além de funcionarem como elementos de estruturação do desenho da "cidade futura", sendo ao mesmo tempo pontos de convergência e difusão do sistema viário, atuam igualmente como fatores de orientação e condicionamento do sentido da expansão urbana, dessa forma funcionando como elementos potenciais de atração do crescimento da cidade, se atentarmos para sua localização, em pontos distantes do 
centro urbano - exceção ao conjunto da administração municipal - dispostos em áreas escassa ou completamente desocupadas nessa ocasião.

Combinando avenidas de penetração, radiais e uma perimetral largamente estendida, o sistema de parkways da zona de expansão se articula à estrutura viária da "cidade existente" a partir da lagoa, com o espelho d'água fazendo às vezes de rotatória, com sua definição orientando-se no sentido de atender às necessidades de circulação que logo se acentuariam com a modernização do porto, cujo movimento até então cruzava o centro da cidade vindo desde Cabedelo através da estrada de Tambaú (avenida Epitácio Pessoa), aberta em 1918 quando se aventou a construção do porto nesse local. Como solução para esse problema, Figueiredo propõe a criação da avenida Miramar cruzando a cidade no sentido norte-sul e partindo do ponto em que a estrada de rodagem que vinha de Cabedelo encontrava a capital, e cujo fim seria recolher o tráfego, especialmente de veículos de carga, conduzindo-o à avenida de contorno, daí fazendo atingir a saída para Recife ao sul ou a estrada para o interior do estado e a estação da Great Western, na área do Varadouro, evitando dessa forma a travessia pelo centro da cidade.

Essa parkway perimetral além de desviar o tráfego da área central, estabelecia os limites máximos de expansão sobre os vales dos rios Sanhauá e Jaguaribe, e neste último caso, protegendo o principal manancial de água potável da capital da aproximação do tecido urbano, que se dava mesmo com o preocupação já manifesta por Saturnino de Brito que em 1923, em ofício enviado ao presidente do estado, Solon de Lucena, referia-se à "necessidade de prontas e decisivas providências para que não prosseguisse a extensão da cidade para a vertente do Jaguaribe, invadindo-se a zona de proteção das águas subterrâneas" (BRITO, 1943:375).

Da mesma forma que no zoning aplicado à "cidade existente", também no caso da zona de expansão urbana o plano reforça as funções associadas à essa parte da capital, que nas proximidades do Parque Solon de Lucena e para os lados dos bairros de Tambiá e Cruz das Armas, se definia por um caráter eminentemente residencial. Estendendo um traçado de quadras regulares ao longo dos eixos viários que estruturam o desenho da área de expansão, foram definidas duas zonas residenciais entre a lagoa e Tambaú, numa ocupação que se daria conforme um padrão de baixa densidade e segundo Figueiredo "dentro dos modernos princípios de cidade jardim, onde o elemento paisagístico predominará"(A UNIÃO, 02/10/1932).

A zona residencial principal desenvolvendo-se entre o Centro de Administração Municipal e o Centro Cívico, até atingir o trecho da parkway perimetral que cortaria a URBANA, V.5, nº6, mar.2013 - Dossiê: Urbanistas e Urbanismo- CIEC/UNICAMP 
cidade no sentido transversal na altura da região da Cruz do Peixe, que por sua maior proximidade com a área urbana estava sujeita às determinações do Código de Posturas. A zona residencial secundária acompanha o percurso da avenida Epitácio Pessoa seguindo uma larga faixa delimitada pela avenida perimetral de contorno, encontrando a leste a avenida Miramar, de onde partiriam outras avenidas radiais que cortariam Tambaú, transformado num bairro balneário, e atingiriam a costa. Além destas, o plano cria uma terceira zona residencial na entrada da capital pela estrada que vinha de Recife, transformada num bairro jardim operário, numa intenção de, melhorando o aspecto desse trecho, criar também um espaço de recepção na cidade, como no caso da Praça de Desembarque.

\section{Conclusão}

Visto no conjunto, o plano de Nestor de Figueiredo embora tenha no porto a origem de sua iniciativa, não encontra nas questões funcionais dele derivadas, de circulação e fluxos, as razões por si determinantes da configuração urbanística. Se isto se verifica no desenho do sistema viário da zona de expansão e naquelas intervenções que procuram ampliar as ligações da área do Varadouro com a parte alta da cidade e daí com o novo centro urbano definido no Parque Solon de Lucena, em que de fato as implicações funcionais do porto exercem maior influência, o traçado e a disposição de certas parkways assumem um caráter que não encontra no porto o único fator. Particularmente, se notadas em sua articulação com aqueles conjuntos de edificações propostos, o que sobressaí é um forte acento formal de caráter monumental.Outro aspecto que fica evidente na leitura do plano de Figueiredo é o tratamento superficial ou mesmo a desconsideração pelo urbanista de problemas urbanos que eram latentes em princípio da década de 1930. Não há qualquer menção ou proposta relativa à infra-estrutura urbana, aos transportes ou à habitação popular, embora sugira um bairro jardim operário numa área da capital já característica por concentrar habitações das camadas populares.

\section{Referências}

BRITO, Francisco Saturnino de Rodrigues de (1943). Saneamento de Paraíba do Norte. In Obras Completas, tomo V. Rio de Janeiro: Imprensa Nacional.

BRUAND, Yves (1999). Arquitetura Contemporânea no Brasil. 3. ${ }^{a}$ ed. São Paulo: Perspectiva. 
BRUANT, Catherine (1996). Donat Alfred Agache: urbanismo, uma sociologia aplicada. In: RIBEIRO, Luiz Cesar de Queiroz \& PECHMAN, Robert Moses (org.) Cidade, povo e nação. Rio de Janeiro, Civilização Brasileira, p. 167-202.

CAMPOS, Candido Malta (2002). Os rumos da cidade: urbanismo e modernização em São Paulo. São Paulo: Editora Senac São Paulo.

COSTA, Angyone (1927). A inquietação das abelhas. Rio de Janeiro: Pimenta de Mello e Cia.

GOODWIN, Philip L. (1943).Brazil Builds: architecture new and old (16521942). New York: MoMA.

LEME, Maria Cristina da Silva (1990). Revisão do Plano de Avenidas. Um estudo sobre o planejamento urbano em São Paulo, 1930. São Paulo: FAU/USP (tese de doutorado)

(org.) (1999). Urbanismo no Brasil. São Paulo, Nobel.

LEVY, Ruth (2010). A Exposição do Centenário e o meio arquitetônico carioca no início dos anos 1920. Rio de Janeiro: EBA Publicações;UFRJ.

MOREIRA, Fernando Diniz (2007). "Urbanismo e modernidade: reflexões em torno do plano Agache para o Rio de Janeiro", Revista de Estudos Urbanos e Regionais, v. 9, n. 2, nov., p. 95-114.

OLIVEIRA, Sônia Maria Queiroz de (org.) (2009). Planos urbanos do Rio de Janeiro: Plano Agache. Rio de Janeiro: Centro de Arquitetura e Urbanismo.

OUTTES, Joel (1997). O Recife: gênese do urbanismo 1927-1943. Recife, Massangana/Fundação Joaquim Nabuco.

PARAÍBA (1932). Administrações dos interventores Anthenor Navarro e Gratuliano da Costa Brito. Decretos de $1^{\circ}$ de Janeiro a 30 de Junho de 1932 Actos do Interventor Federal. João Pessoa: imprensa Official.

PONTUAL, Virgínia (1995). "Ordem e progresso: o pensamento urbanístico no Recife dos anos 30". Anais do6. ${ }^{0}$ Encontro Nacional da ANPUR, Brasília, p. 797-812. REZENDE, Vera (1982). Planejamento e ideologia: quatro planos para o Rio de Janeiro. Rio de Janeiro, Civilização Brasileira.

RIBEIRO, Luiz Cesar de Queiroz e PECHMAN, Robert Moses (org.) (1996).Cidade, povo e nação. Rio de Janeiro, Civilização Brasileira. 
SANTOS, Paulo F. (1977). Quatro séculos de arquitetura. Valença: Editora Valença.

TOLEDO, Benedito Lima de (1996). Prestes Maia e as origens do urbanismo moderno em São Paulo. São Paulo: Empresa das Artes.

TRAJANO FILHO, Francisco Sales (2003). D.V.O.P: arquitetura moderna, Estado e modernização na Paraíba na década de 1930. São Carlos: EESC-USP (Dissertação de mestrado).

XAVIER, Alberto (org.) (2007). Lúcio Costa: sobre arquitetura. 2a ed. Porto Alegre: UniRitter. 